\title{
A EFICÁCIA DA LEI Nº 11.346/2006 (SISTEMA NACIONAL DE SEGURANÇA ALIMENTAR E NUTRICIONAL) DURANTE O REGIME JURÍDICO EMERGENCIAL E TRANSITÓRIO DA PANDEMIA DE COVID-19 (DECRETO LEGISLATIVO $\mathrm{N}^{\circ}$. 06/2020)
}

\author{
Gilberto Fachetti Silvestre ${ }^{1}$ \\ Rafael Breda Cremonini ${ }^{2}$ \\ Luis Henrique Silva de Oliveira ${ }^{3}$
}

\begin{abstract}
RESUMO: Trata-se de pesquisa da qual resultou um artigo de opinião que sustenta a tese de que os entes públicos devem manter restaurantes populares para que pessoas vulneradas socioeconomicamente pelos efeitos da pandemia de $S A R S-C o V-2$ tenham garantido o acesso à alimentação saudável. Para confirmar a hipótese originalmente traçada, a pesquisa verificou sintagmas das formulações normativas da Lei $\mathrm{n}^{\circ}$. 11.346/2006 que estabelecem verdadeiros deveres aos entes públicos, os quais precisam ser concretizados em situações sociais e econômicas especiais. Utilizando-se de uma metodologia baseada em revisão bibliográfica e adaptando, por dedução, a teoria do favor deboli à situação de vulnerabilidade causada pela pandemia, a pesquisa ampliou o conceito do que se entende por vulneráveis no Sistema Nacional de Segurança Alimentar e Nutricional, ampliando o espectro de assistidos pelo SINSA. O objetivo principal foi desenvolver uma tese propositiva e inspiradora que revele a obrigatoriedade de o poder público manter, ampliar ou reabrir seus restaurantes populares para oferecer alimentação adequada às pessoas vulneradas pela Covid-19.
\end{abstract}

PALAVRAS-CHAVE: Sistema Nacional de Segurança Alimentar e Nutricional. Direito à alimentação. Restaurantes populares. Covid-19.

\section{THE EFFECTIVENESS OF LAW N. 11.346/2006 (NATIONAL FOOD AND NUTRITIONAL SAFETY SYSTEM) DURING THE EMERGENCIAL AND TRANSITIONAL LEGAL REGIME OF THE COVID-19 PANDEMIC (LEGISLATIVE DECREE N. 06/2020)}

\begin{abstract}
This is a research that resulted in an opinion article that supports the thesis that public entities should maintain popular restaurants so that people who are socioeconomically vulnerable by the effects of the SARS-CoV-2 pandemic have guaranteed access to healthy food. To confirm the hypothesis originally outlined, the research verified phrases of the normative formulations of Law n. 11.346/2006 that establish real duties to public entities, which need to be implemented in special social and economic situations. Using a methodology based on bibliographic review and adapting, by deduction, the theory of favor

\footnotetext{
${ }^{1}$ Professor da Universidade Federal do Espírito Santo (UFES); Doutor em Direito Civil pela Pontifícia Universidade Católica de São Paulo (PUC/SP); Mestre em Direito Processual Civil pela Universidade Federal do Espírito Santo (UFES); Pós-Doutorado em Educação pelo Centro de Educação da Universidade Federal do Espírito Santo (UFES); Coordenador dos Grupos de Pesquisa "Desafios do Processo" e "Medicina Defensiva"; Advogado.www.desafiosdoprocesso.ufes.br. E-mail: gilberto.silvestre@ufes.br.

${ }^{2}$ Mestrando em Direito Processual pela Universidade Federal do Espírito Santo (UFES); Pesquisador do Grupo de Pesquisa "Desafios do Processo". E-mail: rafaelbcremonini@gmail.com.

3 Mestrando em Direito Processual pela Universidade Federal do Espírito Santo (UFES). E-mail: luishenrique@oliveira-advocacia.com.
} 
deboli to the situation of vulnerability caused by the pandemic, the research broadened the concept of what is understood by vulnerable in the National System of Food and Nutritional Security, expanding the spectrum of people assisted by NSFNS. The main objective was to develop a propositional and inspiring thesis that reveals the obligation for the public authorities to maintain, expand or reopen their popular restaurants in order to offer adequate food to people vulnerable by Covid-19.

KEYWORDS: National Food and Nutritional Security System. Right to food. Popular restaurants. Covid-19.

\section{Introdução}

Esse é um artigo de opinião que apresenta propostas hermenêuticas e soluções equitativas para as dificuldades de alimentação adequada de pessoas vulnerabilizadas pelo contexto social e econômico atuais da pandemia de Severe acute respiratory syndrome coronavirus 2 (SARS-CoV-2). Com isso, pretende-se oferecer um reforço hermenêutico para a melhor operabilidade dos remédios já previstos no Sistema Nacional de Segurança Alimentar e Nutricional (Lei $n^{\circ}$. 11.346/2006), defendendo a existência de um regime deontológico que obriga o Poder Público a fornecer alimentação adequada às pessoas mais vulneráveis por meio dos chamados "restaurantes populares".

Assim, esta pesquisa teve por finalidade investigar os fundamentos de uma tese inspiradora que sustente a obrigatoriedade da implantação dos restaurantes populares nos centros urbanos, com a finalidade de assegurar o direito à alimentação adequada durante a pandemia do coronavírus.

A pandemia do coronavírus tem agravado a situação de vulnerabilidade social, pessoal e econômica vivenciada pela população brasileira, especialmente a mais carente. Com o aumento do desemprego e as recomendações de isolamento, uma parcela da população dependeu e depende exclusivamente do auxílio emergencial fornecido pelo Governo Federal e das doações de outros programas sociais.

A problemática enfrentada pela pesquisa foi o fato de a Covid-19 e as medidas governamentais de contenção da proliferação trouxeram dificuldades de ordem econômica, pessoal e social. Pessoas perderam emprego, tiveram renda decrescida e se encontram em situação de vulnerabilidade. Em razão do aumento dos preços dos produtos alimentícios e da queda da renda, pessoas e famílias inteiras se encontram em condições alimentares inferiores aos padrões estabelecidos na Lei $\mathrm{n}^{\circ}$. 11.346/2006.

Assim, a pesquisa pretende contribuir dogmaticamente para a solução do seguinte problema: já que pessoas se encontram em situação de vulnerabilidade ocasionada pela 
pandemia de Covid-19 e já que o Poder Público tem o dever de garantir a alimentação adequada (Lei nº 11.346/2006), os entes federativos são obrigados a fornecer alimentação em restaurantes populares?

A pesquisa propôs uma tese/hipótese propositiva e inspiradora na qual é defendido que durante o período de vigência do estado de calamidade do Decreto Legislativo ${ }^{\circ}$. 06/2020, os entes federativos terão o dever de fornecer alimentação adequada às pessoas em condição de vulnerabilidade ocasionada pela pandemia de Covid-19, nos termos da Lei no ${ }^{\circ}$ 11.346/2006. A essa conclusão se chega a partir da verificação de formulações normativas da Lei $n^{\circ}$. 11.346/2006 com functores deônticos de obrigatoriedade; logo, fornecer alimentação em restaurantes populares não é uma potestade dos entes públicos, mas um dever, principalmente em épocas de excepcionalidade que extremam a vulnerabilidade das pessoas.

Reforça essa ideia a regula juris do favor debilis, que favorece pessoas vulneradas na interpretação das normas. A partir desse "princípio", a pesquisa dilatou o conceito de vulnerabilidade presente no Sistema Nacional de Segurança Alimentar e Nutricional para além da proteção tão-somente de pessoas pobres, garantindo a assistência a pessoas prejudicadas pela pandemia (seja pela doença, seja pelas medidas governamentais de contenção da proliferação).

Ao final, foi possível formular uma conclusão que confirma a hipótese revela a obrigatoriedade de o poder público manter, ampliar ou reabrir seus restaurantes populares para oferecer alimentação adequada às pessoas vulneradas pela Covid-19.

\section{O Sistema Nacional de Segurança Alimentar e Nutricional: a eficácia deontológica da} Lei no. 11.346/2006.

Essa pesquisa sustenta que existe uma especial eficácia deontológica do Sistema Nacional de Segurança Alimentar (SISAN), criando um dever estatal de promoção ativa de uma alimentação saudável, oponível em face da Administração Pública. Essa perspectiva jurídico-dogmática revela que a Lei n $\mathrm{n}^{\circ}$. 11.346/2006 não é somente uma "carta" de intenções, que estabelece "princípios" destinados a fortalecer interpretações normativas. Assim, essa pesquisa descreverá as principais formulações normativas que compõe o SISAN como comandos deontológicos que determinam a manutenção do funcionamento de restaurantes populares nas cidades que os possuam, em especial no período da pandemia de Severe acute respiratory syndrome coronavirus 2 (SARS-CoV-2). 
A Lei $n^{\circ} .11 .346 / 2006$ criou o SISAN, pela objetivação das "definições, princípios, diretrizes, objetivos e composição" do sistema, impondo um dever ao Poder Público de formular "políticas, planos programas e ações com vistas a assegurar o direito humano à alimentação adequada" $\left(\operatorname{art.} 1^{\circ}\right)$.

Em seu art. $2^{\circ}$, a Lei do SISAN aduz que a alimentação adequada é, in verbis, um “direito fundamental do ser humano, inerente à dignidade da pessoa humana, e indispensável à realização dos direitos consagrados na Constituição Federal”, e impõe a adoção de políticas e ações públicas, pelos entes federados - União, Estados e Municípios - para que seja garantida a segurança alimentar e nutricional da população, com a participação da sociedade civil organizada. Constitui-se, então, o direito à alimentação adequada enquanto um dever jurídico estatal e um direito subjetivo da sociedade brasileira $\left(\S 2^{\circ}\right.$ do art. $2^{\circ}$ e art. $\left.4^{\circ}\right)$.

Segundo Renato Sergio Maluf (1995, p. 134), a segurança alimentar e nutricional é "um conceito que define um objetivo de políticas públicas", de caráter análogo à sustentabilidade e à equidade, que subordina o conjunto de políticas agroalimentares e estabelece os vínculos destas com a política macroeconômica. Por esse enfoque, a segurança alimentar se vincula "com estabilidade no abastecimento dos produtos alimentares e com a manutenção de estoques estratégicos dos alimentos básicos e assume uma especial relevância nos países subdesenvolvidos, onde a oferta de alimentos à população é comprometida, em geral, pela questão da baixa renda da população e pela produção irregular ou insuficientes. Para o autor, nos países da América Latina, o conceito apropriado de segurança alimentar se dá pela garantia do acesso suficiente e regular aos alimentos básicos para a maioria da população à baixo custo, de forma a não comprometer a renda dos cidadãos. Logo, o público alvo das políticas públicas de promoção da segurança alimentar e nutricional são as famílias de trabalhadores e, principalmente, as pessoas que estejam em situação de extrema pobreza, e “como campo de intervenção os determinantes das condições de acesso (emprego e renda) e de produção (estrutura produtiva, disponibilidade e preços) dos alimentos básicos”. Os fatores limitantes da segurança alimentar e nutricional, enquanto princípio de estímulo à promoção da equidade social, são o crescimento econômico e a estabilidade, o comércio exterior, pela importação e exportação de alimentos, e a crise fiscal.

A segurança alimentar, enquanto política pública, deve ultrapassar seus tradicionais limites enquanto política compensatória de desigualdades, apenas, através da formulação pelo Estado de objetivos de longo prazo, pela qualificação e quantificação dos recursos alimentares de forma a atender à população, por meio da comercialização, da distribuição e do acesso a 
alimentos adequados e suficientes. Os governos devem, então, implementar "políticas públicas e estratégias sustentáveis e participativas de produção, comercialização e consumo de alimentos, respeitando-se as múltiplas características culturais do País" (inciso VI do art. $\left.4^{\mathrm{o}}\right)$.

O SISAN é composto por órgão e entidades das pessoas políticas de direito público interno e, também, por instituições privadas, que podem ou não ter finalidade lucrativa, de acordo com a regulamentação do Conselho Nacional de Segurança Alimentar e Nutricional (CONSEA e parágrafos do art. 7. $^{\circ}$ da Lei do SISAN c/c o Decreto $n^{\circ}$. 6.272/2007 da Presidência da República.

As normas jurídicas que orientam o SISAN, a atuação do CONSEA e a implementação da Política Nacional de Segurança Alimentar e Nutricional (PNSAN) regulamentada pelo-Decreto $n^{\circ}$. 7.272/2010 da Presidência da República -, são seus artigos 8. ${ }^{\circ}$ e $9^{\circ}$ de onde se depreendem os princípios e diretrizes regulamentadores do SISAN. No rol de incisos dos dois artigos citados, indica-se: a universalidade e a equidade no acesso à alimentação adequada, vedada a discriminação sob qualquer fundamento; a participação social; a transparência; a intersetorialidade; a descentralização; o monitoramento da situação alimentar a nutricional, para gestão das políticas de governo; a "conjugação de medidas diretas e indiretas de garantia e acesso à alimentação adequada, com ações que ampliem a capacidade de subsistência autônoma da população"; a "articulação entre orçamento e gestão"; e o estímulo à capacitação e à pesquisa.

As normas decorrentes da Lei do SISAN enquadram-se na classificação que Humberto Ávila (2019, p. 104-106) designa de "normas-princípios", uma vez que prescrevem um estado ideal de coisas, compreendido, aqui, enquanto a prestação de uma alimentação adequada, de caráter prospectivo. Os princípios elencados não esgotam as providências a serem tomadas, por parte da Administração Pública e da sociedade civil, em uma atividade coordenada, para que seja atingida a finalidade indicada. Portanto, sua aplicação efetiva depende do estabelecimento de uma correlação entre a adoção de determinados comportamentos, enquanto meios, para que produzam os efeitos almejados e correlatos ao estado ideal de segurança alimentar.

Importa destacar que essa aplicação não é uma potestade (direito potestativo) dos entes federados, mas, sim, um dever de que sejam adotadas as ações necessárias ao atingimento da 
situação — de caráter permanente - de segurança alimentar, por meio do fornecimento de alimentação adequada, saudável, sustentável.

Daí se depreende o caráter deontológico das diretrizes do SISAN, que ultrapassa o plano axiológico - adstrito aos valores, que qualificam positiva ou negativamente determinado elemento - , embora estreitamente com aquele relacionados, uma vez que impõe a adoção das ações necessárias à promoção dos objetivos relacionados à segurança e à adequação alimentar destinadas à população em geral, mas, especialmente, às pessoas mais vulneráveis.

Afirmada a natureza normativa dos preceitos constantes da Lei do SISAN, mostra-se o direito à alimentação saudável enquanto um direito sócio-político individual, que pode ser exigido pelo sujeito enquanto um direito subjetivo em face do Poder Público, que tem o dever jurídico de implementar políticas públicas necessárias e adequadas ao atendimento à disposições legais e suficientes para a promoção da dignidade daqueles que necessitam. $\mathrm{O}$ Estado de Direito garante ao indivíduo a percepção dos direitos prestacionais, tal como é constituído o direito é concebido o direito à alimentação saudável.

Não é outro o sentido da Lei do SISAN quando prescreve em seu art. 3. ${ }^{\circ}$ que o direito à alimentação saudável é como um direito de todos, compreendido o "acesso regular e permanente a alimentos de qualidade, em quantidade suficiente, sem comprometer o acesso a outras necessidades essenciais", com vistas à promoção da saúde, ressalvada diversidade cultural e "que sejam ambiental, cultural, econômica e socialmente sustentáveis". Tal dispositivo legal deve ser interpretado em conjunto com o $\S 2^{\circ}$ do art. $2^{\circ}$, que assim dispõe "É dever do poder público respeitar, proteger, promover, prover, informar, monitorar, fiscalizar e avaliar a realização do direito humano à alimentação adequada, bem como garantir os mecanismos para sua exigibilidade". Fica claro o caráter relacional da relação jurídica regulamentada pela legislação estudada, com o indivíduo podendo exigir do Poder Público que cumpra com o seu dever jurídico de promover a segurança alimentar, quando ficar constatado a ausência ou a deficiência de políticas públicas idôneas para tanto.

Em síntese, não obstante o emprego de conceitos jurídico indeterminados e de cláusulas gerais no âmbito da regulamentação do SISAN, uma vez reduzido a sua vagueza e indeterminação semânticas, conclui-se por apenas uma eficácia possível: o cumprimento de deveres de promoção da alimentação das pessoas vulneráveis. 


\section{A EFICÁCIA DA LEI №. 11.346/2006 (SISTEMA NACIONAL DE SEGURANÇA ALIMENTAR E NUTRICIONAL) DURANTE O REGIME JURÍDICO EMERGENCIAL E TRANSITÓRIO DA PANDEMIA DE \\ COVID-19 (DECRETO LEGISLATIVO №. 06/2020)}

\section{A vulnerabilidade da pessoa na pandemia de Covid-19}

O perfil das pessoas expostas à insegurança alimentar no Brasil está concentrado especialmente nos segmentos sociais em situação de pobreza. São setores vulneráveis seja pela ausência do alimento, seja por má qualidade da alimentação, ou ainda, por condições de vida que impedem a absorção pelo organismo do alimento à disposição. Enquanto consequências da insegurança alimentar são apontadas pela literatura especializada: a fome aguda, consubstanciada na necessidade urgente de se alimentar; e a desnutrição, também denominada de "fome oculta", em razão da inadequação quantitativa ou qualitativa da alimentação cotidiana, ou ainda por alguma moléstia que impeça a absorção biológica dos alimentos ingeridos (MALUF, 2006, p. 6-14).

Essa pesquisa, porém, apresenta uma proposta de abordagem diferente daquela que tradicionalmente é feita em torno da matéria do direito fundamental à alimentação.

Como premissa e referencial teóricos para as investigações, aqui se utilizou o conceito de "vulnerabilidade" da civilística e da processualística contemporâneas. Com isso se trabalhará com uma definição jurídica de "pessoas vulneráveis", que é um conceito mais amplo que aquele da assistência social e das políticas sociais. Nestes últimos campos, a vulnerabilidade é associada à pobreza; já no sentido jurídico, vulnerável se relaciona — em apertada síntese - às desvantagens sentidas pelo sujeito de direito em sua posição perante outros (SILVESTRE, 2020a). Esse será, assim, um dos primeiros reforços hermenêuticos que a pesquisa pretende oferecer: a adaptação do conceito de vulnerabilidade em matéria alimentar a partir dos conceitos da civilística e da processualística, dado que isso é mais favorável àqueles que estão vulnerados pelos efeitos da Covid-19.

O Direito brasileiro contemporâneo tem como uma de suas reguis juris o favor debilis ou favor deboli, um antigo preceito romano que exsurgiu nas legislações atuais nos últimos anos (SILVESTRE, 2020a) (SILVESTRE, 2020b).

Embora originalmente concebido para a proteção da parte devedora, a abrangência do favor debilis desde o medievo tem sido sobre qualquer das pessoas que se encontre em situação de vulnerabilidade (SILVESTRE, 2020a) (GIUFFRÈ, 1987, p. 5-8).

Roberto M. López Cabana (1998) afirma que a causa favorabilis do favor debitoris é a proteção da parte débil de uma relação jurídica. Entenda-se por parte débil aquela que se encontra em uma posição de fragilidade, vulnerabilidade, cuja suportabilidade ultrapassa os padrões do bonus pater familiae (“homem médio") (SILVESTRE, 2020c, p. 8-9). 
A vulnerabilidade (causa favorabilis) decorre da vis fatale cui resisti non potest (força à qual não se pode resistir), que independente da vontade do sujeito e que é imprevisível (SILVESTRE, 2020c, p. 8).

O favor deboli é um remédio jurídico que se destina a mitigar as vulnerabilidades sofridas pelas pessoas, especialmente em tempos de excepcionalidades pandêmicas. O preceito aparece como um critério hermenêutico para analisar a vulnerabilidade alimentar visando a que o direito à alimentação adequada alcance sua finalidade prática objetiva (realização dos preceitos jurídicos) e subjetiva (alimentação saudável) de maneira equitativa.

Mas, o que é vulnerabilidade?

As primeiras preocupações com essa situação desfavorável ocorreram na esfera das obrigações civis, com o desenvolvimento do campo de aplicação da cláusula rebus sic stantibus e da Geschäftsgrundlage, a teoria de revisão contratual decorrente da quebra de comutatividade (OERTMANN, 1921).

A deboleza (ou "debilidade"), em matéria obrigacional, não é entendida necessariamente como pobreza; tem a ver com uma condição de quebra de comutatividade, ou seja, de prejudicialidade de uma pessoa frente à outra (MOREIRA ALVES, 2004) (MOTA, 2006).

É com esse conceito que se quer trabalhar aqui: em razão do favor deboli e das excepcionalidades da situação emergencial e calamitosa, a vulnerabilidade alimentar não pode ser associada apenas à pobreza. Daí que aqui se defende que o direito à alimentação em restaurantes populares não necessariamente será de pessoas pobres neste período de pandemia; será de todos aqueles vulnerados pela circunstância e que precisem de alimentação adequada. Alguns exemplos: há pessoas desempregadas, precisando de auxílio, mas que não são (ou não estão ainda) pobres; há famílias em que a melhor refeição da criança era a merenda escolar; pessoas que ficaram doentes e ainda estão se recuperando.

Outrossim, se o critério fosse tão-somente a pobreza, então deve-se considerar que o auxílio emergencial pago pelo Governo Federal retirou 13,1 milhões de pessoas da pobreza, segundo pesquisa da Fundação Getúlio Vargas, com dados da Pesquisa Nacional por Amostra de Domicílio Contínua Covid-19 (Pnad/Covid-19) do Instituto Brasileiro de Geografia e Estatística (IBGE). Houve uma queda de $20,69 \%$ na proporção da população pobre (BRASIL, 2020). 
Sabe-se, porém, que esses dados se fundamentam em artifícios legais que estabeleceram parâmetros formais-numéricos de pobreza (como a Lei $n^{\circ}$. 10.836/2004), que não necessariamente exprimem boas condições de manutenção.

Então - e em síntese - , a tese aqui sustentada é a de que o direito de acesso a uma alimentação adequada em tempos de excepcionalidades pandêmicas é das pessoas vulneradas pelos efeitos socioeconômicos da pandemia, e não necessariamente de pessoas pobres. (Claro que os pobres estão incluídos nessa categoria). E o fundamento dessa hipótese vai mais além de espeques constitucionais etéreos: encontra-se na base geral do Direito e na regula juris de proteção dos debilis, o favor deboli (SILVESTRE, 2020b).

Assim, com base na concepção civilística de debilidade e vulnerabilidade, considerara-se vulnerável aquele indivíduo posto em situação desvantajosa nas relações jurídicas perante particulares, perante os entes públicos e perante a sociedade (PESCE; SILVESTRE, 2020). É com essa perspectiva que deve ser analisado quem é o destinatário ou beneficiário do Sistema Nacional de Segurança Alimentar e Nutricional da Lei $\mathrm{n}^{\circ}$. 11.346/2006. Será todo aquele vulnerado pela Covid-19 e que depende de ações e políticas públicas para obter alimentação saudável e permanente.

Mas, sói questionar, nesse contexto: quais as principais causas de vulnerabilidades sentidas pelas pessoas nesse período de pandemia? Seguem algumas causas em numerus apertus:

1. Aumento do desemprego (NITAHARA, 2020);

2. Aumento da inflação, o que repercute na queda do poder de compra de itens básicos da alimentação (PIRES, 2020);

3. Queda da renda familiar (MELLO, 2020);

4. Permanência em casa de crianças e adolescentes em tempo integral, em razão da suspensão das aulas presenciais (TENENTE, 2020);

5. Crescimento da violência doméstica, o que implica, às vezes, na saída de algum dos cônjuges ou companheiros do ambiente doméstico (LUCA; GAUDIOT, 2020);

6. Moradia de favor em casa de parentes;

7. Necessidade de investir recursos financeiros em obras de acréscimo (puxadinhos e lajes) para acomodação da família ou de agregados surgidos no período;

8. Aumento dos índices de gravidez; 
9. Adoção de medidas de enfrentamento à contaminação pelo coronavírus; e

10. Enfrentamento da Covid-19 e outras doenças.

Esses fatores destacados não são as vulnerabilidades, mas as causas das debolezas. A debilidade, em si, é condição econômica e/ou de saúde desfavorável que resulta dessas causas (GUSELLA; SILVESTRE, 2020).

Observe que o espectro é aumentado em relação à concepção tradicional do Sistema Nacional de Segurança Alimentar e Nutricional da Lei nº 11.346/2006.

Segundo o relatório constante na Nota Técnica n. 74 publicado pelo Instituto de Pesquisa Econômica Aplicada (IPEA) (SILVA; NATALINO; PINHEIRO, 2020), a população de rua cresceu $140 \%$ durante a pandemia. Estima-se, então, que 222 mil brasileiros não tenham moradia e atuem na economia informal, como, v.g., guardadores de carros, catadores de lixo e vendedores ambulantes.

Portanto, torna-se imperativa a manutenção e a ampliação dos programas de assistência social destinados a essa população extremamente vulnerável, também, mas não somente, com vistas à promoção de uma alimentação saudável e adequada, quantitativa e qualitativamente, na forma da Lei do SISAN e de seus decretos regulamentadores.

O inciso I do art. $3^{\circ}$ do Decreto da PNSAN (Decreto $n^{\circ}$. 7.272/2010) impõe aos participantes do SISAN que priorizem, no momento da execução das políticas de governo destinadas à promoção do direito à alimentação adequada, "as famílias e pessoas em situação de insegurança alimentar e nutricional". Levadas em consideração as circunstâncias excepcionais advindas da pandemia, o argumento pela manutenção do funcionamento dos restaurantes populares que possuem a capacidade de oferecer à população mais vulnerável uma alimentação adequada, nas quantidades recomendadas e com nutrientes suficientes à manutenção da vida humana digna e saudável, já preparados e prontos para o consumo se fortalece, aumentando, por consequência, a carga deôntica do SISAN em todos os atos normativos que os compõem.

\section{O direito à alimentação adequada durante a pandemia: a obrigatoriedade de fornecimento de refeições aos socioeconomicamente vulnerados pela Covid-19}

A legislação federal garante acesso a toda população à alimentação adequada, o que se pode dizer ser um pilar para o mínimo existencial do ser humano. O contexto vivido durante a pandemia da Covid-19, tendo ocorrido levou a um agravamento da situação de 
vulnerabilidade pessoal, social e econômica de muitas pessoas, o que se revela pelos dados informam um aumento na taxa de desemprego e aumento no preço dos itens da cesta básica.

Nesse sentido, as políticas voltadas à alimentação da população, que já são importantes em tempos normais, durante a pandemia da Covid-19, além de se tornar mais relevante ainda, é dotada de urgência em sua implementação.

A política pública de segurança alimentar é especialmente destinada à população em situação de pobreza e extrema pobreza ou em vulnerabilidade social. Este contexto se agravou com a crise sanitária e o advento da pandemia do coronavírus, de forma que a hipossuficiência ou a ausência de renda são fatores determinantes para que um número significativo de pessoas - que se encontram em situação de insegurança alimentar e nutricional —, tenham acesso à alimentação adequada e saudável.

Há trabalhadores, formais ou informais, que residem em áreas distantes de seus locais de trabalho, que necessitam do chamado "restaurante popular" para realizar suas refeições de forma adequada. Logo, o fechamento desses estabelecimentos desassiste parcela da população que deles dependia de forma frequente, pois garantiam sua alimentação ao custo de um preço acessível, nutricionalmente saudável e de qualidade.

Essa demanda é uma profícua oportunidade de aplicação das diretrizes e deveres do Sistema Nacional de Segurança Alimentar e Nutricional (SISAN) da Lei nº 11.346/2006, de modo a confirmar a possibilidade de efeitos concretos a serem produzidos pelo sistema:

O SISAN propõe a formulação e a implementação de políticas e planos de segurança alimentar e nutricional, o estímulo à integração dos esforços entre governo e sociedade civil, bem como a promoção do acompanhamento, monitoramento e avaliação da segurança alimentar e nutricional no país (PINHEIRO, 2008, p. 10-11).

A Lei do SISAN integra diversos atores para a promoção das políticas públicas voltadas a assegurar o direito à alimentação adequada, conforme o caput do art. $7^{\circ}$ :

Art. $7^{\circ}$ A consecução do direito humano à alimentação adequada e da segurança alimentar e nutricional da população far-se-á por meio do SISAN, integrado por um conjunto de órgãos e entidades da União, dos Estados, do Distrito Federal e dos Municípios e pelas instituições privadas, com ou sem fins lucrativos, afetas à segurança alimentar e nutricional e que manifestem interesse em integrar o Sistema, respeitada a legislação aplicável.

$[\ldots]$.

Revista de Direito Sociais e Políticas Públicas | e-ISSN: 2525-9881 | Encontro Virtual | v. 6 | n. 2 | p. $01-18$ | Jul/Dez. 2020. 
Os Estados e Municípios têm a opção de aderir ao SISAN com o fim de obter recursos para implementar as ações voltadas a assegurar a alimentação adequada. Ao fazê-lo estarão vinculados às deliberações políticas dos órgãos que compõem o sistema, inclusive com a necessidade de destinação correta dos valores repassados a título de cofinanciamento das ações voltadas a assegurar o direito à alimentação adequada.

Atualmente, dentre tantas outras políticas públicas que visam a garantir a alimentação adequada da população, esta pesquisa optou por realizar um corte metodológico e se restringir aos restaurantes populares, pertencentes à Rede de Equipamentos Públicos de Alimentação e Nutrição.

Segundo o Ministério do Desenvolvimento Social (MDS) (2020), o Restaurante Popular destina-se a possibilitar uma rede de proteção alimentar em áreas de grande circulação de pessoas que realizam refeições fora de casa, atendendo os segmentos mais vulneráveis nutricionalmente da população. Esse equipamento visa a ampliar a oferta de refeições nutricionalmente balanceadas e seguras, comercializadas com custo baixo. Para melhor ilustrar, veja-se alguns números que traduzem o trabalho do restaurante popular:

No Rio de Janeiro, a primeira unidade estabelecida na cidade foi o Restaurante Popular Betinho, localizado na Central do Brasil. A expectativa era atender, com acesso universal, em torno de 3.000 pessoas por dia, no horário do almoço, com a cobrança de $\mathrm{R} \$ 1,00$ por refeição. No ano de 2016, o estado chegou a servir em torno de 37.000 almoços por dia, nos 16 restaurantes que estavam em funcionamento, cobrando o valor de $\mathrm{R} \$ 2,00$ por refeição servida (SEASDH, 2016) (PADRAO; AGUIAR, 2018)

Todas essas considerações aplicadas ao contexto vivido durante a pandemia do Covid19, o equipamento se faz mais necessário que antes. Tem o condão de criar impacto imediato na sociedade, fornecendo alimentação de qualidade tanto para famílias carentes quanto a moradores de rua. Estes últimos, a propósito, vivem em situação de vulnerabilidade extrema, visto que outros equipamentos - como o Banco de Alimentos, que fornecem cestas básicas às pessoas -, não atendem a esse público.

Observe, agora, o art. $2^{\circ}$ in totum da Lei ${ }^{\circ} .11 .346 / 2006$ :

Art. $2^{\circ} \mathrm{A}$ alimentação adequada é direito fundamental do ser humano, inerente à dignidade da pessoa humana e indispensável à realização dos direitos consagrados na Constituição Federal, devendo o poder público adotar as políticas e ações que se façam necessárias para promover e garantir a segurança alimentar e nutricional da população.

$\S 1^{\circ} \mathrm{A}$ adoção dessas políticas e ações deverá levar em conta as dimensões ambientais, culturais, econômicas, regionais e sociais. 
$\S 2^{\circ}$ É dever do poder público respeitar, proteger, promover, prover, informar, monitorar, fiscalizar e avaliar a realização do direito humano à alimentação adequada, bem como garantir os mecanismos para sua exigibilidade.

As formulações normativas do caput e dos parágrafos do art. $2^{\circ}$ adotam sintagmas com functores deônticos que expressam manifestamente a obrigatoriedade de adoção de ações e medidas para garantir a segurança alimentar das pessoas. Toma como razão para a ação e referencial hermenêutico a consideração dos diversos fatores ambientais, culturais, econômicas, regionais e sociais que ensejam o dever de alimentar os que precisam.

É neste ínterim que se aplica a vulnerabilidade das pessoas decorrente da pandemia como dimensão econômica, regional e social $\left(\S 1^{\circ}\right)$ que ensejará o dever de medidas adequadas para garantir a segurança alimentar. E uma dessas medidas adequadas - inclusive prevista como equipamento básico do SISAN — é o restaurante popular, que nesse período deveria ser aberto, reaberto ou ampliado.

\section{A experiência no município de Vitória-ES}

Há uma experiencia vivida com o restaurante popular do município de Vitória, capital do Estado do Espírito Santo, que pode ilustrar a tese aqui defendida e confirmar a hipótese desta pesquisa. Trata-se do procedimento administrativo $\mathrm{n}^{\circ}$. 2018.0022.7571-05, que tramitou na $11^{\mathrm{a}}$ Promotoria de Justiça Cível de Vitória, o qual originou o pedido de tutela cautelar antecedente que tramita perante a $4^{\mathrm{a}}$ Vara da Fazenda Pública Estadual, Municipal, Registros Públicos, Meio Ambiente e Saúde de Vitória sob o nº 0012979-25.2020.8.08.0024.

O Município de Vitória implantou, em 2005, o equipamento público intitulado Restaurante Popular, incluído no rol de serviços da segurança alimentar, cujo objetivo era o fornecimento de duas mil refeições diárias à população. No ano de 2006, a Prefeitura implantou outro equipamento público, intitulado Banco de Alimentos Herbert de Souza, localizado em espaço cedido pela Conab, no bairro Jardim da Penha.

Após anos de funcionamento de ambos, a Prefeitura de Vitória encerrou as atividades do equipamento em dezembro de 2016.

Em 2017 a Secretaria Municipal de Assistencial Social de Vitória concorreu a um edital do Ministério do Desenvolvimento Social para modernização do Banco de Alimentos, o qual exigia que esse equipamento tivesse espaço próprio. Assim, para atender à exigência 
expressa no edital, a Secretaria Municipal de Assistência Social optou por utilizar o espaço edificado especificamente para funcionamento do Restaurante Popular.

Como foi abordado no pedido formulado perante o Judiciário, essa adequação do espaço ocorreu contra as recomendações do CONSEA-ES e do COMSEA de Vitória e não houve a participação popular nessa tomada de decisão. As recomendações contrárias destes órgãos têm especial relevância, uma vez que o Estado do Espírito Santo aderiu ao sistema nacional e criou seu Sistema Estadual de Segurança Alimentar e Nutricional Sustentável por meio da Lei Complementar Estadual no 609/2011.

Por sua vez, o Município de Vitória aderiu ao SISAN e instituiu o Conselho Municipal de Segurança Alimentar e Nutricional por meio da Lei Municipal nº 6.364/2005, responsável pelo exercício do controle social dessa política pública.

O restaurante popular, embora atenda pessoas de outros municípios, não representa um ônus para a capital capixaba; pelo contrário: representa segurança alimentar para pessoas vulneráveis que possuem vínculo com a cidade e contribuem diariamente com a composição fiscal do município.

O Ministério Público Estadual e a Defensoria Pública Estadual expediram Recomendação à Prefeitura de Vitória pugnando pela reabertura do restaurante popular, considerando os efeitos econômicos e sociais da pandemia da Covid-19 na vida das pessoas de baixa renda, estudantes, desempregadas, subempregadas e aposentadas.

Todavia, mesmo diante de todos esses acontecimentos e da irregularidade da suspensão das atividades do restaurante popular - que ocorreu sem a realização de consulta popular e contrariando todos os posicionamentos dos órgãos consultivos competentes —, o município de Vitória realizou contratação de empresa para a realização de obra que descaracterizaria, por completo, o prédio do restaurante popular - realizando por completo o desmonte do equipamento - , para abrigar o banco de alimentos.

Restaurante Popular e Banco de Alimentos da Família possuem finalidades distintas e que se complementam para alcançar o mesmo objetivo, quais sejam:

1. Restaurante popular: tem o objetivo de ampliar a oferta de refeições nutricionalmente adequadas, com preços acessíveis à população de baixa renda, vulnerabilizados socialmente e em situação de insegurança alimentar e nutricional. Visa também promover a alimentação adequada e saudável valorizando os hábitos alimentares regionais; e 
2. Banco de alimentos: realiza a distribuição de cestas de alimentos às famílias em vulnerabilidade social/alimentar e nutricional, bem como desenvolve atividades de caráter socioeducativo destinados ao público que atende.

Sob o fundamento de que seria um retrocesso a substituição de um equipamento pelo outro - já que o ideal seria a implementação de ambos simultaneamente, para atender as diretrizes do Plano Nacional de Segurança Alimentar —, foi ajuizada a medida cautelar antecedente para a prefeitura se abster de desmontar o aparelho do restaurante popular, na forma do art. 303 do Código de Processo Civil.

De imediato, foi deferido o pedido de urgência formulado sob os seguintes argumentos:

- eficácia normativa do direito à alimentação como direito social, previsto no ar. $6^{\circ}$ da Constituição da República;

- Lei $n^{\circ}$. 11.346/2006 assegura o direito a alimentação adequada e a criação do Sistema Nacional de Segurança Alimentar;

- Lei Complementar Estadual no 609/2011 assente o dever do Poder Público de adotar as políticas e ações que se fizerem necessárias para promover e garantir a segurança alimentar e nutricional da população;

- Lei Municipal no 6.364/2005 criou o Conselho Municipal de Segurança Alimentar e Nutricional - COMSEA-Vitória, que é responsável pelo exercício do controle social da política pública; e

- vedação ao retrocesso social caracterizado pelo desmonte do equipamento.

Com o deferimento da medida, o Ministério Público informou que pretende dialogar com o município para viabilizar a reativação voluntária do equipamento. Caso isso seja infrutífero, ajuizará a Ação Civil Pública para assegurar o cumprimento da obrigação.

\section{Conclusão.}

O Sistema Nacional de Segurança Alimentar e Nutricional da Lei nº. 11.346/2006 lida com um conceito de vulnerabilidade restrito à baixa condição econômica e social da população brasileira, o que acaba sendo adstrito à noção de pobreza e de pobreza extrema.

Ocorre que o $\S 1^{\circ}$ do art. $2^{\circ}$ da Lei do SINSA prescreve que as políticas de segurança alimentar e de acesso à alimentação adequada devem levar em consideração dimensões de ordem ambientais, culturais, econômicas, regionais e sociais. Isso deve ser interpretado como 
a necessidade de sobrelevar fatores circunstanciados na elaboração daquelas políticas. Quer dizer, a conjuntura criada pela pandemia de Covid-19 e as medidas de contenção da proliferação do coronavírus não só podem como devem ser consideradas, de modo a adaptar ações da política alimentar desenvolvida pelos entes públicos ao suprimento de necessidades alimentícias de pessoas vulneradas pelas repercussões socioeconômicas da pandemia.

Para garantir alimentação a todos aqueles que necessitam — dadas as circunstâncias do momento - , a regula juris do favor debilis oferece importantes contribuições para compreender o que caracteriza a vulnerabilidade e quem pode ser considerado vulnerável. Por isso o referencial teórico conta com trabalhos da literatura contratualista (cível e consumerista).

Assim, a pesquisa trouxe o conceito de vulnerabilidade da civilística e da processualística contemporâneas — que é influenciado pelo favor debilis — para considerar como destinatário das políticas de alimentação do SISAN, neste momento, não somente as pessoas pobres, mas todas aquelas vulneradas pela pandemia de Covid-19 e que sofreram queda substanciosa na sua qualidade de vida.

O Sistema Nacional de Segurança Alimentar e Nutricional tem por destinatário todos aqueles que necessitam ter garantida a segurança alimentar e a alimentação adequada. $\mathrm{Na}$ atual circunstância, tais destinatários não se restringem, necessariamente, às pessoas pobres.

Dentre os equipamentos do SISAN, os bancos de alimentos e os restaurantes populares são aqueles que podem, de maneira emergencial, garantir com mais eficiência a alimentação adequada àqueles atingidos pela crise econômica, social e sanitária. E, aprofundando na temática dos equipamentos do SISAN, foi possível perceber que existem deveres dos entes públicos de garantir a alimentação saudável que podem ser cumpridos por meio de fornecimento de refeições em restaurantes populares. Ou seja, a manutenção de restaurantes populares é um dever que se impõe ante à ampliação do espectro de pessoas vulneradas e com alimentação prejudicada.

\section{Referências bibliográficas.}

ÁVILA, Humberto. Teoria dos Princípios Jurídicos: da definição à aplicação dos princípios jurídicos. 19.ed. São Paulo: Malheiros, 2019.

BRASIL, Cristina Indio do. Estudo aponta que auxílio emergencial tirou 13,1 milhões da pobreza. Pesquisa se baseou em dados da PNAD Covid, do IBGE. Agência Brasil. Rio de Janeiro, 26/08/2020. Disponível em <https://agenciabrasil.ebc.com.br/geral/noticia/2020- 


\section{A EFICÁCIA DA LEI №. 11.346/2006 (SISTEMA NACIONAL DE SEGURANÇA ALIMENTAR E NUTRICIONAL) DURANTE O REGIME JURÍDICO EMERGENCIAL E TRANSITÓRIO DA PANDEMIA DE \\ COVID-19 (DECRETO LEGISLATIVO №. 06/2020)}

08/estudo-aponta-que-auxilio-emergencial-tirou-131-milhoes-da-pobreza>. Acesso em: 13 set. 2020.

BRASIL. Ministério do Desenvolvimento Social e Combate à Fome. Secretaria Nacional de Segurança Alimentar e Nutricional. Rede de equipamentos públicos de alimentação e nutrição. Disponível em:

http://www.mds.gov.br/webarquivos/publicacao/seguranca_alimentar/Redeequipamento_SA Npdf.pdf. Acesso em: 14 set. 2020.

CABANA, Roberto M. López. Defensa jurídica de los más débiles. In: Revista de Direito do Consumidor, vol. 28, São Paulo, p. 7-21, out./dez., 1998.

GIUFFRÈ, Vincenzo. Il "favor debitoris": araba fenice. In: VI Congreso Latino-Americano de Derecho Romano, Mérida, Venezuela, 5-8 agosto 1987.

GUSELLA, Gabriela Azeredo; SILVESTRE, Gilberto Fachetti. Direito (e necessidade) de renegociação dos contratos de consumo em razão das consequências socioeconômicas da Covid-19: aspectos materiais e processuais. In: DIAS, Luciano Souto; TARTUCE, Fernanda (Orgs.). Coronavírus: direitos dos cidadãos e acesso à justiça. Indaiatuba-SP: Foco, 2020, v. 1, p. 245-256.

LUMIA, Giuseppe. Elementos de Teoria e Ideologia do Direito. Trad. Denise Agostinetti. São Paulo: Martins Fontes, 2003.

MALUF, Renato Sergio. Segurança alimentar e desenvolvimento econômico na América Latina: o caso do Brasil. Brazilian Journal Of Political Economy, São Paulo, v. 15, n. 1, p. 134-140, jan. 1995. Disponível em:

https://rep.org.br/rep/index.php/journal/article/view/1230/1215. Acesso em: 13 set. 2020. MELLO, Celso Antônio Bandeira de. Curso de Direito Administrativo. 34.ed. São Paulo: Malheiros, 2019.

MOREIRA ALVES, José Carlos. O favor debitoris como princípio geral de direito. In: Revista Brasileira de Direito Comparado, nº 26, Rio de Janeiro, p. 03-23, jan./jun. 2004. MOTA, Mauricio. A proteção decorrente do favor debitoris como princípio geral do direito das obrigações no ordenamento jurídico brasileiro. In: Quaestio Iuris, v. 3, Rio de Janeiro, p. 49-108, 2006.

OERTMANN, Paul Ernst Wilhelm. Die Geschäftsgrundlage - Ein neuer Rechtsbegriff. Leipzig: Scholl, 1921. 
PADRAO, Susana Moreira; AGUIAR, Odaleia Barbosa de. Restaurante popular: a política social em questão. Physis, Rio de Janeiro, v. 28, n. 3, e280319, 2018. Disponível em $<$ http://www.scielo.br/scielo.php?script=sci_arttext\&pid=S0103$73312018000300614 \& \operatorname{lng}=$ pt\&nrm=iso $>$. Acesso em 14 set. 2020. PESCE, Edoardo; SILVESTRE, Gilberto Fachetti. Il governo del contrato ai tempo del Covid-19: clausola rebus sic stantibus e favor debilis tra Italia e Brasile. In: CAMPOS, Adriana Pereira; MAZZEI, Rodrigo (Orgs.). Questões jurídicas decorrentes da Covid-19: processo, tribunais e tratamento de conflitos. Vol. 02. Curitiba: Juruá, 2020, s/p.

PINHEIRO, Anelise Rizzolo de Oliveira. Reflexões sobre o processo histórico/político de construção da lei orgânica de segurança alimentar e nutricional. Rev. Seg. Alim. e Nutric. Campinas, v. 15, n. 2, p. 1-15, 2008, Acesso em 13 set. 2020. Disponível em: https://periodicos.sbu.unicamp.br/ojs/index.php/san/article/view/1813/1866. SCHULZ, Fritz. Principios del Derecho Romano. Madrid: Civitas, 1990. SILVESTRE, Gilberto Fachetti. Din România în lumea occidentală: datoria de a renegocia în Codul Civil român pentru protecția vulnerabilităților contractuale. Articol nepublicat. În ediție (presă). Vitória-ES, Brazilia, 2020a.

SILVESTRE, Gilberto Fachetti. De bescherming van contractuele kwetsbaarheid: vergelijkingen tussen Braziliaanse en Belgische wetgeving. Ongepubliceerd artikel. In editie (pers). Vitória-ES, Brazilië, 2020b.

SILVESTRE, Gilberto Fachetti. Novos problemas, antigas soluções: o amplo significado da cláusula rebus sic stantibus e a renegociação, a suspensão e a conservação dos contratos cíveis e mercantis. In: Civilistica.com - Revista Eletrônica de Direito Civil, v. 9, n. 1, p. 126, 2020c.

SOTO, Erika Isler. Del favor debilis al favor consumatore: consideraciones históricas. In: Derecho PUCP, n. 82, Lima, junio-noviembre, p. 35-59, 2019. 